\title{
UNIVERSITYOF
}

FORWARD

THINKING

WESTMINSTER用

WestminsterResearch

http://www.westminster.ac.uk/westminsterresearch

Cars, Driving, Landscape, and the Architectural Gaze

Law Michael John

NOTICE: this is the authors' version of a work that was accepted for publication in Journal of Historical Geography. Changes resulting from the publishing process, such as peer review, editing, corrections, structural formatting, and other quality control mechanisms may not be reflected in this document. Changes may have been made to this work since it was submitted for publication. A definitive version was subsequently published in Journal of Historical Geography, 41 (July 2013) 86-89.

Journal of Historical Geography is available online at:

https://dx.doi.org/10.1016/j.jhg.2013.04.001

(C) 2013. This manuscript version is made available under the CC-BY-NC-ND 4.0 license http://creativecommons.org/licenses/by-nc-nd/4.0/

The WestminsterResearch online digital archive at the University of Westminster aims to make the research output of the University available to a wider audience. Copyright and Moral Rights remain with the authors and/or copyright owners.

Whilst further distribution of specific materials from within this archive is forbidden, you may freely distribute the URL of WestminsterResearch: ((http://westminsterresearch.wmin.ac.uk/)).

In case of abuse or copyright appearing without permission e-mail repository@westminster.ac.uk 


\section{Cars, Driving, Landscape, and the Architectural Gaze}

Kathryn A. Morrison and John Minnis, Carscapes: The Motor Car, Architecture, and Landscape in England, Yale University Press, 2012, 438 pages, £40 hardcover.

Iain Borden, Drive: Journeys Through Film, Cities, and Landscapes, Reaktion Books, 2013, 280 pages, £18 paperback.

In the last twenty years academic interest in cars and driving has grown to the point that we can now set aside protestations that the car is such a normalised part of everyday life that it has been rendered invisible. Sociologists, historians, and geographers have produced telling insights into the car's role in the production and consumption of material culture, as a means of societal domination, as a despoiler of the environment, and as a provider of excitement and danger. Attention is now also being directed to our post-petroleum future and its implications.

One aspect of cars and driving that has promoted some exciting work is their relationship with landscape. In the 1970s the dominance and significance of the car in American life prompted two important works. Reyner Banham's homage to the Los Angeles freeway system in book (Los Angeles: The Architecture of Four Ecologies, London 1971) and film (Reyner Banham Loves Los Angeles, 1972) demonstrated that American life could now be truly experienced only from inside a car, and that the feelings resulting from driving at high speed or crawling along in a traffic jam presented a unique opportunity for appreciation of a modernistic landscape. Robert Venturi's Learning from Las Vegas: the Forgotten Symbolism of Architectural Form (London, 1977) explored the roadside iconography of that singular city. A full twenty-five years later Peter Wollen and Joe Kerr edited Autopia (London, 2002) a wide- 
ranging collection of essays on cars and culture, many of which considered the relationship between driving and landscape.

More recently, perhaps provoked by a heightened level of sociological enquiry into automobility, several writers have also considered the historical and contemporary links between cars, driving, and landscape. Peter Merriman's study of the production and consumption of the M1 (Driving Spaces: $A$ Cultural-Historical Geography of England's M1 Motorway, London, 2007) positions that road as enfolding the practices of those who built and drive on it, while C. Mauch and T. Zeller's World Beyond the Windscreen (Athens, Ohio, 2008), an edited collection of largely historical essays on the landscape of roads in Europe and the USA emphasises their national and political origins. Joe Moran's On Roads (London, 2009) addresses landscape more obliquely in his eclectic history of driving on British roads.

The two books under review here, by scholars from an architectural background who have added to this canon, provide further evidence of the centrality of driving to our modern, western lives, through its impact on the built environment and through the cinema's representation of driving. Both books aim to explore the relationship between driving and landscape.

Carscapes looks at the historical impact of buildings and roads on the English landscape, plotting the journey from the early years of motoring to the present day. Drive takes a wider, international view of landscape, showing it in both the close-quartered perspective of the road that is found in cities and in the transcendental and kinaesthetic experiences of the vanishing point of the open road.

Carscapes, by Kathryn Morrison and John Minnis, architectural historians and investigators with English Heritage, presents the history of 'innovations in architecture and infrastructure' generated by motoring in England. ${ }^{1}$ It is a heavy book, hard to hold up to read with over 400 quarto pages and 300 illustrations. Such is the quality of its illustrations that it can be read as a coffee-table book, but those interested in the authors' research will be rewarded by its detailed commentary. The authors draw on material from

\footnotetext{
${ }^{1}$ Carscapes: The Motor Car, Architecture, and Landscape in England, New Haven and London 2012, Press release, http://yalepress.yale.edu/OtherVendors.asp?isbn=9780300187045, [accessed 19 March, 2013
} 
English Heritage's National Monuments Record photographic archives, recently taken photos of old buildings, aerial photos, advertisements from motoring magazines, and well-executed maps to illustrate their narrative. The book's first part uses the clever idea of the 'Life cycle of the car' to emphasise the consumption and materiality of automobility. The eight chapters covering the life cycle begin with manufacture and end in how cars are recycled. The second part of the book, 'Driving around', considers the driving experience and addresses, from an architectural standpoint, the interaction of the motorist with his or her surroundings. Two of the chapters from part one and three chapters from part two give a particular flavour of the book. In chapter two, 'Selling cars', Kathryn Morrison leads the reader through the history of car retailing from its origins in England in 1896 to the present day. As in the first part as a whole, the story is told through a history of the buildings used for selling cars, though, surprisingly, it does not discuss the impact of these buildings on the landscape. Morrison accurately records the appearance of each building, but does not exercise much in the way of aesthetic or affective judgement. This is particularly apparent when she discusses the car showrooms of the 1970s and the 1980s, a period which has so far escaped the nostalgic gaze of the car enthusiast. One execrable Peugeot garage is described simply as 'a ubiquitous arrangement, recurring up and down the country' (p. 69). The depth of research is apparent throughout and is seen at its best when it is used to show the co-location of early car showrooms in London's Great Portland Street (p. 56). This illuminating discussion shows the concentration of economic activity that quickly sprang up in the early part of the twentieth century and stimulates the reader to tramp up and down that street to find what is left of them. Stricter editing might have removed the diagrammatic layouts of car showrooms in Streatham and Piccadilly, where the exact positioning of cars for sale is set out without any explanation of its significance - if there is any. The chapter is lifted throughout by the very high quality of the illustrations that catch the eye and make the reader reluctant to return to the text.

In chapter five, 'Filling up', John Minnis narrates the architectural history of English filling and petrol stations from the 1900s to the present. For this reader the section on the debate on the character of the filling station during 
the 1930 s is the most interesting and goes some way to meeting the book's objective of examining the impact of the car on its wider landscape. Minnis sets out, in text and an excellent selection of photographs, the 1930s debate between competing versions of Englishness that influenced the appearance of public roadside buildings. Tension between a nostalgic bucolic imaginary and the forces of modernity sit at the heart of this discussion of the car and its associated landscape. Discussion of changes in petrol station design in the 1950s and 1960s focuses on a particularly interesting period in motoring history, when mass ownership of cars began and American retailing ideas exerted increasing influence on British roads. It would have been useful and more consistent with the pre-war section of this chapter to have considered the aesthetic aspects of filling station design and how they contribute to the modern roadscape. Oddly, the last forty years of filling up are relegated to about two pages, despite the fact that disused petrol stations, rendered uncompetitive by supermarket petrol stations, now litter the landscape. Chapter ten, 'The car and the countryside', is an extended essay on the heated debate on the interaction of modern car drivers and the real and imagined rural in inter-war England. As Minnis acknowledges this subject has received much academic attention, led by David Matless with Landscape and Englishness (London, 1988) who identified the moral geographies of the period that regulated the behaviour of parvenu motorists in the countryside. Minnis illustrates this idea with some telling images and examples. He gives short shrift to elite motoring before the First World War and his discussion of the car's profound impact on rural life after 1945 is confined to a single page. This is a strange set of omissions as elsewhere in the book the authors are careful to produce a complete narrative history from the late 1890s to about 2010. It would have been very revealing to consider the recent relationship between the car and the countryside, when a reduction in public transport has made car use a necessity, and increased personal mobility has led to profound changes in village life.

Chapter eleven, 'Hospitality for the motorist', also led by Minnis, is an engaging history of the provision of food, drink, and overnight accommodation for England's car drivers. It takes us through the development of hotels and tearooms designed to attract the passing motorist, and gets up to full speed 
on the peculiar developments of the late inter-war period, where motor hotels, roadhouses, and progressive pubs were built alongside England's major roads. In considering developments after the Second World War, Minnis turns his attention to the motorway service station. This is a good choice as these service stations epitomised a democratic modernity in the 1960s and 1970s with designs that ranged from the plain and simple bridge at Charnock Richard to the brutalist Forton with its concrete '65 foot restaurant tower... resting on a horizontal stalk' (p. 314). Service stations' dominating presence over the motorway makes them a key part of the landscape of driving at speed in England.

Carscapes' generally celebratory review of the architecture occasioned by wider car usage gives way in chapter thirteen, 'Traffic in towns since 1945', to a sense of apology and regret as Kathryn Morrison considers the way in which inner-city road schemes of the 1960s to the 1980s ruined both city centres and the lives of nearby residents. Morrison carefully situates the development of urban roads within the modernising planning agenda of postwar Britain when slum clearance and bomb site rebuilding combined with a desire for modern, efficient transport networks to overtake the apparently nostalgic and backward-looking wish to retain ancient city centres intact. Morrison extends this analysis to the protest against the extension of the $M 3$ over Twyford Down in the 1990s. This final chapter leaves Carscapes with a feeling of chances missed and poor choices made - a feeling unrelieved by the short conclusion that argues that the future of roadside architecture lies in exurban formation which would further prejudice the economic health of city centres.

In Drive by lain Borden, professor of architecture and urban culture at the Bartlett School of Architecture, University College London, attention is turned from the architecture and material artefacts of the car, to how driving as a cultural practice can be understood through its widespread representation in the cinema. Borden has written on the relationship between architecture and space in, for example, Skateboarding, Space and the City: Architecture and the Body (Oxford 2001) and, taking Henri Lefebvre's argument about the production of space, shown how architecture is not just visible, but is experienced by people through their practices and resistance to create new 
spaces. In Drive he argues that driving is the normalised way we encounter landscape today.

Drive is divided into four long chapters, each with a short sub-sections exploring related sociological themes. The chapters are based on the speed of the cars involved - a dromological approach that is clever and revealing. 'Cities' looks at low-speed urban driving; 'Journeys' moves faster and away from the city to the open road of the imagination; 'Motopia' considers the highspeed driving of the American freeway and the less glamorous British motorway; and 'Altered states' looks at very high-speed transgressive driving. Borden largely relies on American, British, and French cinema for the examples he uses. Drive's high quality glossy paper allows its 97 illustrations to be faithfully reproduced in the text, albeit at a small scale.

In the opening chapter, 'Cities', Borden first considers the gendered aspects of driving, and the relationship between driving, gender, sex, and love is a theme he returns to throughout the book. In the short section on 'Men and women drivers' the impression made on readers is almost filmic in itself as series of movie titles flies past their eyes. In his first 250 words Borden introduces four different movies; La Glace à Trois Faces (1927), Alfie (1966), Thunder Road (1958), and White Lightning (1973). Here the book becomes a directory for students wanting to explore movies on certain themes, despite Borden's disavowal in the introduction of such a purpose, and we sense a tension between writing essays on major movies to provide deeper insights or giving a comprehensive but more superficial exposition. Borden, the owner of a bibliographical database on driving with 100,000 entries (p. 12), is, like the authors of Carscapes, enthusiastic about details and deeply knowledgeable. For each movie we learn exactly which type of car is involved. So for Carry on Cabby (1963) we are told (some of us already knew) that Hattie Jacques's cabbies drove a Ford Cortina Mk. 1. This information might be useful for readers more interested in cars than landscape, but for others, like me, may find it distracts from the themes of the book. In the sub-section on 'Adventure and fun' Borden takes a different approach and presents a short essay on how city driving provokes exciting imagery in the original and remake of The Italian Job (1969 and 2003). His detailed strada per strada analysis of the original film's stunt driving connects the playful behaviour of the British thieves 
with Rome's sights and sounds. In considering the clumsier, Americanised remake Borden uses the fact that the movie's stars did their own stunts to examine the nature of reality in cinema - a theme he returns to later in the book.

In his second chapter, 'Journeys', Borden's narrative accelerates with an exposition of the cinematic representation of the kinaesthetics and existentialism associated with driving. The chapter starts with a short historical discussion of British cinema and the road. Claude Friese-Green's colour documentary The Open Road (1926) and the, even at the time of its release, cloyingly nostalgic Genevieve (1953) introduce the idea that driving in Britain was connected to exploration. This sits oddly with the rest of the chapter whose exposition of the later twentieth-century road movie is dominated by American examples. This is not surprising: a vanishing point on the road from Newbury to Hungerford doesn't quite cut it; a sisterly plunge over the Cheddar Gorge still less so. There is something about the open road in movies that appeals to the American psyche and to the British imaginary version of America. Borden works movies such as Vanishing Point (1971), Easy Rider (1969) and Thelma and Louise (1991) into an account of how movies about cars and the road can be used to connect actual and metaphorical journeys, for example driving through an empty landscape to suggest alienation.

In the third chapter, 'Motopia', Borden considers the world of the freeway. He starts with a discussion of futuristic interpretations of fast, long-distance motoring. Motopia (1961) is eclipsed in importance by Lang's Metropolis (1927) and Bel Geddes's Futurama exhibition of 1939, because of its obscurity and origin in Britain, where freeway building was slow to develop. It would be hard to imagine a German author referring to Motopia, but here it is used to set up some later contrasts between placelessness on British and American roads. Borden sets out familiar arguments for freeways as placeless, empty, and meaningless, but does not mention the rebuttal of this idea by Peter Merriman (an author Borden admires) and Tim Cresswell who inverted the idea that motorways and airports are non-places by considering them from the less privileged viewpoint of workers such as taxi drivers who 
see them in quite a different way. ${ }^{2}$ Perhaps this is a consequence of the driver-centric view of cinema, where motorway service station workers are cyphers who never emerge from the background. Borden then considers the separate and unique landscape of the motorway and freeway in a more general essay whose argument is less reliant on movies and which discusses the ideas of Banham and Venturi (see above). The chapter then turns to the experience of freeways and motorways, where driving is hypnotic and sends the driver into a trance-like state, disconnected from the exciting time/space compression associated with modernity.

In the final chapter 'Altered states', Borden considers the 'transcendence, transgression, car chases and crashes' associated with high-speed driving in films (p. 167). He is on very solid ground here, even if his protagonists aren't. Car crashes and chases are a staple film device for lending excitement by changing the pace of the screenplay. To illustrate the point Borden explains in interesting short essays how Bullitt (1968), The French Connection (1971), and Crash (1996) used speed for cinematic effect. What is even more interesting is Borden's use of documentary films to make his points. The infamous French short film, C'était un rendezvous (1976), which records an illegal race around central Paris, and Grand Prix (1966), which employed Formula 1 footage, are used to explain some of the karma like states induced by very high speed. The use of these films sits uneasily with the discussion on cinematic reality in fictional movies that Borden appends to the previous chapter. A separate study of documentary films of driving might have revealed more than fictional movies, but perhaps they are too real, too lacking in the artifice the viewer needs to connect emotionally with what is being shown.

Borden recognises this problem and makes a plea for more inter-disciplinary and non-representational analysis of cars and driving. Drive is the antithesis of a non-representational account of driving and cars, being brim full of Borden's opinions on others' cultural productions. It is, though, an interdisciplinary study, which blends insights from sociology, cultural geography,

\footnotetext{
2 T. Cresswell, On The Move: Mobility in the Modern Western World, London 2006; P. Merriman, 'Driving Places: Marc Augé, Non-Places, and the Geographies of England's M1 Motorway', Theory, Culture and Society, 21:4/5, 2004: 145-167
} 
and media studies, with architecture kept below the surface - though, as his work on skateboarding has shown, Borden is a far from conventional architectural commentator.

Drive examines the world of cars portrayed in film, with its inherent morphing of subject and object, driver, car, and road. Film is a good choice to represent the dynamic assemblage of the components involved in driving. The adoption of the closed car in the mid to late 1920s insulated the driver from the landscape and attenuated the sensational and embodied aspects of driving, promoting a stronger sense of connection between the car and its driver. The narrow windscreens of closed cars restricted the driver's view of the surrounding landscape, something which, on the long, straight American roads shown in the movies, gives the impression that the driver is stationary and the car fixed, while the scenery rushes towards him or her - something which recursively mimics the experience of sitting in a movie theatre. ${ }^{3}$ In this respect the movies described in Drive closely resemble our own feelings of driving in cars. Movies can, though, by cutting from the interior of a car to long shots or helicopter shots of the car, liberate the audience from this restricted view. This object/subject switch differentiates movies from our own driving and produces a heightened sense of landscape, reminding us that movies are a representation as contrived as those in literature or popular music. Sometimes it is possible to forget that Drive is a representation of representations of driving, such is the force of filmic imagery.

Cinematic techniques make movies at once more evocative and less informative than real life. A solution to the limitations of movies' ability to interpret the landscape of driving could, as Borden suggests, be found in nonrepresentational accounts which rely on participant's videos or diaries to record the experience of being in the car. Unlike in the movies, the observer remains fixed in the confines of the car and records a consequently attenuated but more realistic view of landscape. A difficulty with these approaches in that when they record typical quotidian experiences the results are so familiar as to be dull and disengaging - like the party bore who tells

\footnotetext{
${ }^{3}$ T. Dant, 'The Driver-Car', Theory, Culture \& Society, 2004, 21:4/5
} 
you in great detail what route he took to get there - while atypical experiences tell us little of what driving means in the everyday world. ${ }^{4}$

Drive and Carscapes have a particular point of view for their landscape. Movies are mostly the driver's story, so, as described earlier, the point of view for many movies is the driver's seat from which the world appears through a windscreen and disappears rapidly in the rear window or rear view mirror. This driver-centricity allows Drive a celebratory power that privileges the mobile protagonists. Imaginary high-speed transgression is only exciting, liberating, and without consequences if the other participants in driving are reduced to cyphers. Here, cinema and real life diverge. Driving has many unwilling participants: old people struggling to cross the road, children who can't play outside, those too poor to escape the consequences of road schemes. Ignored by cinema, their landscape is marginalised and forgotten. Carscapes is, for the most part, a straight narrative of architectural history, concentrating on recording in great detail the important buildings and structures associated with driving in England. The second part of the book is less a 'book of record' than is part 1, and starts to embrace the idea that cars liberate some but punish others. This softens the disciplinary rigidity typical of books of this nature, but the effect is partial and not followed through. Had it been, it could have achieved a more complex understanding of this contested aspect of twentieth-century England. Carscapes promises, in its title and publisher's press release, an insight into how 'automobiles have shaped the modern English landscape'. ${ }^{5}$ Whether you think this has been achieved depends largely on what you mean by 'landscape'. As John Wylie has shown, here is a term of myriad meanings and possibilities. ${ }^{6}$ Ironically quite what a carscape is, is something that Carscapes barely addresses in part 1 and tackles only tangentially in Part 2 . It is, perhaps, significant that the book's index has no entry for 'landscape' but does have one for 'landscaping'

\footnotetext{
${ }^{4} \mathrm{E}$. Laurier et al., 'Driving and 'Passengering': Notes on the Ordinary Organization of Car Travel', Mobilities, 3:1, 2008, pp. 1 - 23

${ }^{5}$ Yale University Press, press release accompanying Carscapes, http://yalebooks.co.uk/display.asp?K=9780300187045, [accessed 19 March, 2013] ${ }^{6} \mathrm{~J}$. Wylie, Landscape, Abingdon, 2007.
} 
and yet has nineteen sub-headings for 'garage'. There is no suggestion here that landscape is something to be practised or experienced. The first part of Carscapes, in particular, sets out a landscape that might have survived a neutron bomb - where all the people are dead, but all the buildings have survived.

The beautifully reproduced photographs in Carscapes were, mostly, taken at quiet times of day, and in good light; yet to meet the authors' aim of building our understanding of the landscape of cars, we would have needed blurred images, glimpsed casually through the side window of a car, framed by the windscreen supports. In part two of Carscapes, the impact of driving on the topography of England is shown through aerial photographs of the patterns of the road on the surrounding countryside - a pilot's but not a driver's view of landscape. The authors of Carscapes do, though, in their discussions of the impact of controversial rural and urban road schemes, acknowledge that not everything about driving can be seen from the driver's seat.

Drive is a moderately-priced, well-illustrated, and engaging book that is recommended for readers interested in how movies help us understand the experiences and emotions of driving in cars and how drivers experience landscape. Although this was not the author's intention, it also provides the reader with an instructive catalogue of future viewing possibilities. This investigation of how film represents landscape might well stimulate a complementary and most welcome examination of the representation of driving in literature. Carscapes is a less thought-provoking read than Drive, and, despite its title, says little about the way landscape is experienced, but is a very welcome collection of photographs and essays on the infrastructure of England's motoring history. It is an expensive book, but one that will find favour with architectural libraries and readers with a specialist interest in the history of the car.

Our understanding of the way that the landscape of roads and buildings is seen through the windscreen of our cars is still very much in development. Much work remains to be done to explain the meanings of this illusive but highly normalised way of seeing the world. 
Michael John Law

Department of Social and Historical Studies

University of Westminster 309 Regent Street, London W1B 2UW 